\title{
Participation in Inclusive Learning and Teaching Practices in Higher Education: A Qualitative Study of Academic Staff Identity and Change
}

\author{
Victoria L. \\ O’Donnell \\ University of the \\ West of Scotland, \\ $U K$
}

\author{
Jane Tobbell \\ University of \\ Huddersfield, UK
}

\author{
Chris Bradshaw \\ University of the \\ West of Scotland, \\ $U K$
}

\author{
Elizabeth \\ Richmond \\ University of the \\ West of Scotland, \\ UK
}

\begin{abstract}
This paper presents data collected as part of a research project carried out at the University of the West of Scotland, UK. The research explores inclusive learning and teaching practices within the context of Higher Education (HE). The paper presents data collected using a qualitative, semistructured interview approach with staff. Using distributed socio-cultural explanations of learning and development, the research seeks to develop our understanding of the complex process of cultural change within HE towards inclusive practices, through an investigation of the proximal and distal systems which serve to construct individual action and identities, the relationships between those systems, the valued practices of the community of $H E$, and the barriers and enablers to participation in that community.
\end{abstract}

\section{Introduction}

In 2011, the UK Higher Education Academy (HEA) launched a one-year developmental change program called 'Developing an Inclusive Culture in Higher Education'. Whilst not a contested notion per se, there is no single unified understanding of inclusion in HE learning and teaching. The HEA define an inclusive learning and teaching culture as one which enables all students to develop academically, professionally and personally to fulfill their potential. Such a culture should take various factors into account at all levels, from curriculum design to academic practice. Some of these factors relate to equality legislation, which identifies certain 'protected characteristics' within UK law (age, disability, gender reassignment, marriage and civil partnership, pregnancy and maternity, race, religion and belief, sex, sexual orientation). Under the UK's Equality Act it is unlawful for a person to be disadvantaged as a result of one of these 'protected characteristics'. The implications for UK Higher Education Institutions is that they must ensure that adjustments are made within the learning, teaching and assessment environment to ensure that individuals are not disadvantaged due to one or more of these 'protected characteristics'. These legislative drivers are only one part of the move towards creating a more inclusive learning and teaching culture. A truly inclusive culture should also take into account other factors which contribute to the diversity of the student body, such as learning styles, socio-economic status, educational history or family circumstances. However, much of the literature on inclusion in HE still focuses on the experiences of and the provision which is made for specific 'protected' groups, particularly disabled students (e.g. Fuller et al., [1]; Claiborne et al., [2]).

Internationally, the HEA's definition of inclusion resonates with the multiculturalist movement. Multiculturalism seeks to reform educational systems in order to ensure equality of opportunity and social justice for all students, and ultimately looks for social reconstruction and societal change. Some of that work examines multiculturalism within the context of HE specifically (e.g. Baumgartner \& Johnson-Bailey, [3]; Cuyjet et al., [4]). Despite its name, true multiculturalism has come to mean more than diversity in relation to only race or culture, but is about diversity in its entirety, and is therefore to be distinguished from work whose focus is solely on cultural diversity. Multicultural education is about "moving beyond simple acknowledgement of diversity to a social reconstructivist critique" (Riehl, p65 [5]). Perhaps the political agenda which lies at the core of multiculturalism explains why it is not often mentioned in the context of inclusive higher education in the UK, where the focus is on shifting learning and teaching practices, policy and pedagogy. However, the ultimate goals of both the multiculturalist and inclusive agendas are converging in relation to higher education, since both are seeking to create environments which provide equality of opportunity for participation by all.

Waterfield and West [6] provide a useful definition of an inclusive approach to learning and teaching in $\mathrm{HE}$, as distinct from two other approaches: the 'contingent' approach (where special arrangements are made for particular students, such 
as extra time in an examination, but where the students are still required to assimilate into the existing learning and teaching systems) and the 'alternative' approach (where different arrangements are made for any students who require them, such as written materials being offered in place of verbal ones). In contrast, a truly inclusive approach offers a flexible range of learning, teaching and assessment methods for all students, which are planned from the outset and built into the design of the curricula.

Despite these useful conceptualizations, previous research suggests that academics are still working with varied individualized understandings or interpretations of inclusive learning and teaching (May \& Bridger, [7]), such as the adjustments made to accommodate disabled students, the assimilation into $\mathrm{HE}$ of under-represented socio-economic groups, the making of special arrangements for applicants without traditional entry requirements, providing support for international students, or supporting mature students. These different understandings represent 'alternative' or 'contingent' approaches as defined above, and what seems clear then is that the HEA's definition of an inclusive culture and Waterfield and West's view of an inclusive approach to learning and teaching, do not represent understandings of inclusion in $\mathrm{HE}$ which are shared by institutions, nor by individual academics.

\section{Research background}

The University of the West of Scotland (UWS) was one of 16 institutions chosen to participate in the HEA's program. As the first stage in this research project, a self-evaluation tool was completed by UWS senior academic management, to establish their views about the current situation with regards to the institution's development of an inclusive culture. The results revealed that at the level of senior academic management, the University felt that it was already making good progress towards the development of an inclusive culture. The existence of a large number of policies, strategies and initiatives (for example an equality plan, a policy on student parents, widening participation initiatives with schools from under-represented areas, a policy for care-leavers) provided evidence of the University's commitment to the development of an inclusive culture, and were therefore seen as evidence of shifts in the practices of the institution. However, subsequent discussions with individual academics revealed that many were unaware of the existence of some of these policies, strategies and initiatives, and even fewer were familiar with their content. Academics were also unsure how these policies or strategies should be translated into concrete actions in the form of changes to their everyday teaching, learning and assessment practices.

An analysis of the policy and strategy documentation also revealed a lack of a consistent and shared understanding of inclusion. Whilst some of the policies were general, many pertained to specific groups or individuals, and suggested different arrangements, different support mechanisms or different processes to be applied when working with such groups. Viewed in this way, such policies represent a shift from the 'contingent' approach outlined above, but they still perpetuate the 'alternative' approach rather than representing a shift towards a truly inclusive culture, with flexibility of opportunity for all. A comparative study carried out by Osborne [8] revealed a similar lack of consistency in approaches to widening participation (as opposed to inclusion) across six countries. That research classified widening participation initiatives into three distinct groups. Inreach programs focus upon attracting potential students to the institution. Out-reach programs involve partnerships with outside organizations such as schools, employers and the community. But neither of these two approaches represents true systemic and structural re-organization to allow full participation by all. This, Osborne refers to as flexibility in programme provision, and such changes represent the kind of approach which would be necessary for an institution to develop a truly inclusive culture.

HE learning and teaching practices, whilst enacted by individual academics, are nevertheless embedded in societal and cultural practices. May and Bridger [7] argue that cultural change towards more inclusive practices in HE require institutions to focus simultaneously on both individual and institutional factors, since these cannot be seen in isolation of each other, "as they operate as two sides of the same coin” (May \& Bridger, [7]). By this they mean that institutions must address inclusion in both a top-down way and a bottom-up way, making changes at policy level and at the level of learning and teaching practice in order to develop an inclusive culture. But without shared understandings of inclusion and inclusive practice, such a two-pronged approach is still unlikely to succeed.

However, we would argue that the nature of change and development in higher education practice is far more complex than even this two-pronged approach suggests, and have observed previously that $\mathrm{HE}$ learning and teaching practices do not always reflect the dogma of how learning and teaching should occur (O’Donnell, Tobbell, Lawthom \& O’Neill, [9]). Recent work exploring inclusive pedagogy in schools suggests that even teachers committed to the principles of inclusion may be constrained by the implicit values and assumptions embedded within the systems in which 
they work (Florian \& Black-Hawkins, [10]). We would argue that the process of cultural change within HE requires more complex and distributed socio-cultural explanations of learning and development than a "top-down" and "bottom-up" combination can offer. The practices of higher education cannot be understood at the level of an individual teacher, department or even an institution. Understanding the practices of higher education requires an understanding of the proximal and distal systems which serve to construct individual actions, and of the relationships between those systems. It also requires an understanding of the community of practice of higher education, the valued practices of that community, and the barriers and enablers to participation in that community.

\subsection{Project aims}

Following on from this first stage of the project, the research presented here sets out to explore more fully the complex relationships between staff conceptualizations of inclusion, their manifestations in learning and teaching practice, the impact of organizational policies towards inclusion upon individual practice, and the factors which enable or prevent shifts towards inclusion in HE learning and teaching. The specific aims of this paper are to explore:

1) the nature of learning and teaching practices within $\mathrm{HE}$ with regards to inclusion;

2) the ways in which changes in policy or strategy towards inclusivity serve to construct inclusive practices within the HE community, and;

3) the factors which enable or prevent individual staff's participation in such practices.

\section{Socio-cultural theory and higher education practice}

Bronfenbrenner ([11]; [12]) argues for an understanding of development and change that takes into account the microsystems, mesosystems, exosystems and macrosystems which combine to construct individual development and change. This recognizes the importance of individual actions as constructed and reconstructed by personal, social and societal contexts, and acknowledges that these change over time. Microsystems include the patterns of activities, roles, and interpersonal relations experienced by individuals in particular settings. Mesosystems are the inter-relations between the various microsystems in which an individual participates. Exosystems are those which an individual may not directly experience, but which nevertheless exert an indirect influence upon an individual, and macrosystems are the overarching characteristics of culture or broader societal contexts.
Wenger's ([13]) Communities of Practice (CoP) theory allows for an exploration and an understanding of learning communities in terms of valued practices, participation and change. This theoretical framework is an established lens through which to view data which explores the subjective experience of valued practices by individuals participating in a learning community, and the role of those practices in understanding development and changes within the community as a whole (O’Donnell \& Tobbell, [14]; Tobbell \& O’Donnell, [15]; Tobbell, O’Donnell \& Zammit, [16]). The theory takes account of the active engagement of all participants, with the tasks and practices which construct the university. Learning and behavior are re-conceptualized in this theoretical approach as being distributed across the range of experiences and relationships, past and present, in which an individual has engaged or in which s/he is engaging. From this theoretical perspective effective environments can be conceptualized with reference to the practices that serve to promote or discourage participation. A shift towards inclusive learning and teaching practices would therefore come about as a result of the gradual inculcation of all members of the community into a new set of shared and valued practices, rather than as an immediate response to a new policy or strategy initiative.

\section{Methodology}

Following the imperatives generated by the theoretical frameworks above, a critical realist perspective (Sayer, [17]) underpins the project's research methodology. This implies that both the empirical (that which individuals personally experience) and the actual (that which influences experience, but is not directly experienced by individuals) are crucial for understanding. The project in its entirety therefore explores the reported experiences of students and staff of UWS as an inclusive institution through semi-structured interviews. These complement the understanding of the macro-level perspective gained from a selfevaluation tool completed by senior academic managers, and from the document analysis of university strategy and policy.

The university is comprised of three academic Faculties. A total of 26 participants took part in the project in its entirety (10 students; 10 members of academic teaching staff; six academic senior managers). Participants from all three of these groups were spread across all three of the academic Faculties.

This paper focuses upon data collected through the semi-structured interviews carried out with academic staff. The analysis was conducted inductively using a grounded theory approach. Data were analyzed using a constant comparative 
technique, being read and coded by the principal investigator and another member of the programme team, who were seeking to identify key emergent themes (Merriam \& Simpson, [18]; Strauss \& Corbin, [19]). Comparisons were made between the different interpretations within and between the data sources and the themes were revised and refined. The analysis took a focused problem approach, rather than an open problem approach (Anderson, 2002 [20]) since the CoP framework and ecological model within which the research is positioned informed the analysis as it took place.

\section{The data: acceptance and resistance}

From the large amount of data collected, one key theme will be presented and discussed here - that of Acceptance and Resistance. The analysis which follows explores the roots of this theme in terms of academic identity and of perceived barriers to participation in inclusive practice.

What was clear from the data was that all staff interviewed felt positive in relation to the philosophy of inclusion in HE learning and teaching. Several of them noted its centrality in terms of the University's vision and mission, and all expressed the view that inclusivity as a general principle was one which they agreed with. In terms of participants' individual understandings or working definitions of what is meant by inclusion in an HE context, as expected based on previous research, some staff focused more on aspects of disability and the adjustments which need to be made to learning, teaching and assessment practices in order to meet the requirements of students with particular support needs. However, most participants went beyond this in acknowledging the importance of considering diversity in all its forms, including students who enter HE from the Further Education (FE) sector, mature adult students and international students. Within their interviews, some staff gave examples of learning and teaching practices which could be considered as highly inclusive, although they did not themselves describe or conceptualize these as examples of 'inclusive' practices, but merely as 'good' practice.

Despite this, what emerged was evidence of a fairly widespread resistance on the part of the staff interviewed, to making any deliberate, concrete, practical changes to their learning and teaching practices, which would serve to create a truly inclusive culture. Despite expressing agreement with the idea of creating a learning and teaching culture which allows all students to participate equally, staff would then continue to perpetuate discourses around the idea that students who are 'different' should have to assimilate into the existing system. This represents the 'contingent approach' discussed previously. These present within the data as interesting contradictions, and some specific examples of these are discussed below.

One participant expressed a more sophisticated understanding of inclusion than others, and went beyond the more basic 'contingent' approach discussed earlier, in saying that inclusion is:

“...about maybe just making sure you've got a bit of variety in your teaching and what you're doing, so that there is, you know, hopefully something that everyone can take from it."

This same participant, however, when asked what concrete changes they had put in place to provide this kind of variety, said:

"I've not actually changed anything completely, we often are governed by what's in the module descriptor. But I think that for some students they could probably do with differing assessments. But then you might end up designing a whole load of assessments that are probably not comparable. I'm not sure if any institution would do that, or if it's practical."

These perceived barriers to inclusion will be discussed in the next section, but as discussed earlier, the availability of a flexible range of assessment options would be precisely the kind of practice which would fit with an inclusive approach, if staff were prepared to make the necessary changes to their practices to enable such an approach. This illustrates one of the ways in which staff may hold views which are accepting of the need for an inclusive culture, whilst simultaneously resisting the changes which they could enact to facilitate one.

To illustrate this theme further, what follows is an excerpt from an interview with a different participant, whose understanding of inclusion focused much more closely on accommodating the needs of disabled students, or those who require additional support for their learning. Nevertheless, this narrower conceptualization still expressed a very positive view of the need to accommodate such students in order that they might participate fully in HE learning and teaching:

"I always sort of think of [inclusion] meaning assisting people to get the most out of their education so that they can get, so things like learning support, and things like using scribes, doing what we can as academics to make sure that people have the material to go on. It's not so much about creating an even playing field, but creating more equality."

This excerpt shows the philosophy of inclusion being articulated in line with the legislative drivers (representing the broader macrosystem) relating to the 'reasonable adjustments' which should be made for those with additional support needs due to disability. The university itself has, in response to these macro level drivers, put in place processes to ensure that the legislation is complied with. This is achieved through a system whereby students who declare a disability or some other issue which may 
affect their learning, have their needs assessed and then staff who are responsible for teaching these students are sent details of the adjustments which should be made for that student in order to accommodate them.

However, despite what is said above, this same participant, in discussing the forms which they have been sent detailing students' additional needs, says:

"...I think I've had in total about 15 to 20 additional needs things, and I have to be absolutely honest and say that I tend not even to open them any more..."

This shows that despite the university's own processes (the exosystem) which are designed to ensure that legislation is complied with, the institution does not become more inclusive unless changes are enacted at the level of individual academic practice.

Another participant discussed inclusion in relation to the challenges faced by international students:

"I think sometimes my accent is so broad that there was foreign students and particularly students who don't have English as their first language. I occasionally find myself worrying a little bit about that. That they won't understand the accent. And certainly lectures probably for students who are, English isn't their first language, lectures probably aren't the best of all the potential learning tools."

This reveals a thoughtful consideration of some very practical issues which may prevent full participation in the learning and teaching environment by students whose first language is not English, and it also reveals some awareness of the pedagogical issues which might be taken into consideration in planning which teaching methods might best facilitate learning and engagement by such students. However, despite this awareness and concern about the extent to which international students are being accommodated in the learning environment, the same participant simultaneously admitted to a reluctance to engage with the issue of internationalizing the curriculum itself:

"I always sneak around it by saying, 'We're doing [global issues] in trimester two', but in actuality [global issues] means European, North American and the concept of global things."

Thus, we see an acceptance of the principles of inclusion in relation to the participation of international students, yet with a simultaneously held resistance to making changing to academic practices which would enact such principles and enable such participation.

Analysis of the data suggests that the roots of these apparent contradictions lie in individual academic identities, and also in real or imagined tensions between the individual academics and the university exosystem. This analysis is explored in the following section.

\section{Analysis}

\subsection{Academic identity}

What emerged from the analysis of the data was a clear sense that whilst academics spoke positively about the principles of inclusion in HE learning and teaching, they often felt that taking the necessary steps to make changes to academic practices which would create a more inclusive culture, was out with their remit. They frequently suggested that enabling student participation in the practices of the learning community is something which should be facilitated by other 'remedial' support services as an add-on to the student's everyday encounters with learning, teaching and assessment, rather than something which should be achieved through changes to those everyday encounters themselves. For example, one participant suggested that their role as an academic was to be an expert in a particular subject area, and that they did not view themselves as someone sufficiently skilled as a teacher to be able to support diverse students who might experience challenges in engaging with a traditional approach to HE learning:

"We're academics... we know how to recognize someone who's struggling, but we don't have the teaching skills to assist someone who is struggling."

As discussed in Section 1, good practice in inclusive learning, teaching and assessment would suggest that offering diverse methods of assessment should be encouraged in order to allow different types of students to demonstrate their knowledge, skills and understanding, since different types of students may find different types of assessment more or less challenging than others. It is interesting to note that within the UK there has recently been movement towards the professionalization of teachers in HE, and most UK universities now offer postgraduate certificates in teaching and learning in $\mathrm{HE}$ (or equivalents) which can (and in some cases must compulsorily) be undertaken by new academics. UWS offers one such qualification which has been compulsory for new academics joining the institution since 2008. That program of study covers inclusive learning and teaching within its curriculum, but in itself may not be sufficient to challenge or to shift academics' sense of identity and of what it means to be a teacher in HE.

Another participant, whilst acknowledging that offering a flexible range of assessment opportunities would represent good inclusive practice, indicated that they would still not move away from a reliance on academic essays because these were central to the traditional notions of what it means to 'read' for a degree and how knowledge has traditionally been expressed within the academy:

"...learning to write an essay is as much a part of a, to me, I know I'm very old-fashioned, but it is an academic rite of passage." 
We know from previous research (e.g. O’Donnell \& Tobbell, [14])] that whilst academics place a high value on the practice of writing essays, the process by which someone should actually go about writing one is often perceived by students themselves as something hidden. Understanding what an essay is, how it should look and be presented, how it should be structured, and the processes of using evidence and referencing to develop an argument, are not simply learned unproblematically by students. Essay writing is experienced by students as a practice which is not explicitly explained nor taught, but one which they are simply expected to grasp from the outset. As illustrated by the quote above, participants in this study often expressed the view that essay writing is a valued practice within the HE community, and those students unable to engage successfully in that practice should not be a participant in the community. Consistent with previous research, participants also often expressed the view that their role as academics should not be to facilitate engagement with that practice, but that such engagement should be facilitated by other nonacademic student support services, such as the effective learning service.

The use of various non-academic support services was mentioned by participants as essential in terms of facilitating student participation in the $\mathrm{HE}$ community, again because of the perception that this is out with the role of an academic, and because academics do not have the time to support students themselves. But participants also felt that students should be seeking this kind of guidance themselves, if they experience challenges in engaging with or understanding various academic practices. One participant said:

"So there is this over-reliance on the kind of academic who is at the coal-face in a sense... and they'll direct you to $x, y$ and $z$, education guidance or whatever."

Consistent with previous research (Tobbell, O’Donnell \& Zammit, [16]), academic staff often expressed the view that students should be selfsufficient, independent learners, and that students should not require support from academic staff, to facilitate their engagement in the practices of the community. However, previous research has indicated that the notion of what it is to be an independent learner is not one which is transparent to students, and that they do not always understand what is meant by this, nor what is really expected of them. Within Communities of Practice theory, such reluctance on the part of academics to allow students access to the practices of the community, would represent a significant barrier to their participation. Academics represent the 'old-timers' in the community, and as such they are the ones who are expert in its valued practices. Without an opportunity to learn from old-timers, new participants will be unable to become full participants in the community, and will therefore remain legitimate peripheral participants only. Yet the data collected here suggest that academic identities do not always include a sense of responsibility for the inculcation of new participants.

Thus, there is an acceptance of the principle of inclusion as important, but a simultaneous resistance to changing practices which would lead to a more inclusive culture, because academic identities often do not include a sense of responsibility for making such changes.

\subsection{Perceived barriers to inclusive practice}

Another part of this project in its entirety involved the collection and analysis of university policy and strategy related to inclusion. These presented a positive picture of the university's response to, and strategic management of, inclusion at the level of the university exosystem. Nevertheless, these documents and their implications were not perceived by participants as enabling shifts towards more inclusive practice. In fact, participants in this study, as well as many other members of academic staff surveyed out with the project, were not at all familiar with the content of these documents, and many were not even aware of their existence. Participants expressed the view that even finding time to engage with such documentation was not possible, and should not reasonably be expected of academics. One participant said:

"I think people are working really hard, and you just wonder, how much more can we ask of them?"

Despite this, participants spoke positively and coherently about the principle of inclusion in HE and considered critically what kinds of shifts in practice would be required for the university to move towards a more inclusive learning and teaching culture. This suggests that the development of an inclusive HE learning and teaching culture depends upon individual actions within an ecological system, and that such individual actions are not straightforwardly affected by the influence of the exosystem. The inter-relationships between different parts of the system are complex, and individual practices will not shift simply as a result in changes at the level of the exosystem. Another participant said:

"It's like, you know, this is changing, that's the policy now, how do you know about the policy? Well, you know, we've got 156 of them and they've been wheeled round through the internet and we've to go and look at it."

This expresses a fairly widespread resentment towards the sheer volume of policies generated by the institution, and some staff had clearly reached a point where they had disengaged from the process of keeping up with changes in policy. 
As discussed previously, participants were often very aware of the shifts in their individual practices which would be required to bring about a more inclusive culture, but resisted taking the practical steps required to make those changes. Sometimes the explanations for not making such changes were expressed in terms of perceived constraints placed upon them as individuals by HE's approach to learning and teaching. For example, students are often required to attend a minimal number of face-toface teaching sessions, with the rest of their learning time being made up through independent study. As discussed earlier, though, students do not always understand what it is to study independently. Materials and resources might be made available on the university's virtual learning environment, but without guidance as to what to do with those materials or how to engage with them, students may not be able to participate fully in learning. For example, one participant said:

"...nine hours of contact and the rest of the time you're expected to engage with the material independently, at home... I'm not sure that we do them any favors, we don't encourage participation outside of those nine hours..."

It is possible to argue, however, that individual academics are the ones with the power to change these kinds of practices, and that they could make changes themselves to the teaching timetable, the content of learning and to the pedagogical resources and materials provided, to encourage such participation, if they felt it would bring about greater levels of participation. It seems clear, though, that many academics simply accept the traditional approach to learning and teaching as the norm, instead of challenging or changing aspects of that approach which are within their control. In Section 5 above, one academic expressed resistance to making modifications to assessments in line with inclusive practice by saying that the nature of assessments is governed by the module descriptor. In fact, the module leader can make changes to the module descriptor, and is therefore in control of its content. At UWS, the making of changes to module descriptors as a way of encouraging inclusive practices have been promoted through changes to quality enhancement procedures, as well as through staff development sessions offered to academics across the institution. Thus, the barriers to inclusive practice which are perceived by staff as explanations for their resistance could, in reality, be easily overcome.

Further research should usefully extend this work beyond the focus on inclusive practice, to explore more fully the factors (real or perceived) which prevent academics from enacting changes to their learning and teaching practices generally, even despite their own awareness of the benefits which such changes would bring about.

\section{Discussion}

As stated in Section 2.1, the threefold aims of this paper were to explore: 1) the nature of learning and teaching practices within $\mathrm{HE}$ with regards to inclusion; 2) the ways in which changes in policy or strategy towards inclusivity serve to construct inclusive practices within the HE community, and; 3) the factors which enable or prevent individual staff's participation in such practices.

In analyzing the data, it is clear that, consistent with other areas of HE (O’Donnell et al., [9]), academic practice in relation to inclusion does not consistently reflect rhetoric or policy. And in fact, academics may agree with inclusive policy and rhetoric whilst simultaneously engaging in practices which are inconsistent with inclusion. In line with Osborne's ([8]) research into approaches to widening participation, approaches to inclusion vary; and although an approach might be viewed as inclusive, it will not be truly inclusive approach without structural and systemic shifts taking place within an organization. Our suggestion that even a combination of 'top-down' and 'bottom-up' approaches to inclusion within an $\mathrm{HE}$ institution (May \& Bridger, [7]) are still unlikely to bring about such structural and systemic shifts, is borne out by the data presented here. As an organization, UWS has taken a strong strategic approach to inclusion, and at the level of individual academics there is a clear commitment to the principles of inclusion, but nevertheless the data support the notion that even these two approaches in combination have not brought about consistent shifts in learning and teaching practice.

Communities of Practice theory (Wenger, [13]) provides a useful lens through which to view these inconsistencies and suggests that their roots may lie in academic identities. The data suggest that understanding the valued practices of the $\mathrm{HE}$ community, and the facilitation of student participation in those practices, is key to understanding aspects of academic identity which may prevent shifts towards inclusive learning, teaching and assessment practice. A greater understanding of these aspects of academic identity should allow the HE sector more broadly to consider its approach towards bringing about changes which are likely to lead to genuine shifts towards inclusive practice, as opposed to merely changing policy. Further research should explore the processes by which organizational change and development occurs within HE institutions generally. This would assist with a broader conceptual understanding of $\mathrm{HE}$ institutions as Communities of Practice, and would also be helpful for managers and staff developers.

The impact of the macrosystem, in terms of broader external, societal and government influences, 
upon the university exosystem is clear. The exosystem expresses a vision for inclusion through policy and strategy, which is clearly important in terms of providing a backdrop to the institution's goals. However, the concretizing of these at the level of learning, teaching and assessment practice clearly depends upon individuals and groups of academic staff. Consistent with Florian \& BlackHawkins' ([10]) research with schoolteachers, even academics who are committed to inclusion feel constrained by the values and assumptions which are implicitly embedded in university learning and teaching systems. These constraints may be real or perceived, but either way they serve as a barrier to changing practice. Further research might usefully explore the processes by which perceived constraints can be identified and challenged, in order to facilitate academic staff towards shifts in their practices.

Some staff are engaging in inclusive practice without necessarily recognizing it as such, and many are unaware of the policies and strategies anyway. Therefore, the more complex ecological model of development and change which Bronfenbrenner ( [11]; [12]) provides is useful for conceptualizing the different ways in which influence upon individual action can be understood within a university context, and within broader societal contexts. Thus, sociocultural perspectives applied to higher education have allowed for a greater understanding of the complexities of the processes of development and change within higher education.

\section{Conclusions}

On the basis of the data and analysis presented here, we suggest that the process of shifting learning and teaching practice within a university context is likely to be a gradual one, as members of the community together develop a new set of valued practices, and as new members are inculcated into those practices. Resistance to such changes due to their perceived impact on workload, academic identity or perceived organizational constraints, will prevent new practices being valued by the community and thus present barriers to change. One potentially useful avenue for future enquiry might be to explore in more depth, inclusive practices which are not being labeled as such, and which are instead simply being identified as 'good practice'. Enabling staff to recognize such practices as beneficial and helpful to the learning community as a whole may bring about required shifts in relation to which practices are valued, and help staff to recognize these in terms of their contribution to inclusion.

By exploring the understandings and experiences of all levels of academic staff and of students, this research will allow for the emergence of a more comprehensive picture of the process of development and cultural change towards inclusive learning and teaching practices, and towards organizational change in higher education more generally, which combines several key theoretical perspectives and which will allow for a move beyond the picture presented by policy and strategy documentation and by individual experiences alone.

\section{References}

[1] M. Fuller, J. Georgeson, M. Healey, A. Hurst, K. Kelly, S. Riddell, H. Roberts, and E. Weedon, Improving Disabled Student Learning in Higher Education: Experiences and Outcomes, Routledge, London, 2009.

[2] L.B. Claiborne, S. Corforth, A. Gibson, and A. Smith, "Supporting students with impairments in higher education: Social inclusion or cold comfort?", International Journal of Inclusive Education, 15(5), pp513-527, 2011.

[3] L.M Baumgartner, and J. Johnson-Bailey, "Fostering awareness of diversity and multiculturalism in adult and higher education”, New Directions for Adult and Continuing Education, 120, pp45-53, 2008.

[4] M.J. Cuyjet, M.F. Howard-Hamilton, and D.L. Cooper (Eds.), Multiculturalism on Campus: Theory, Models and Practices for Understanding Diversity and Creating Inclusion, Stylus Publishing, Herndon: VA, 2011.

[5] C. Riehl, "The principal's role in creating inclusive schools for diverse students: A review of normative, empirical, and critical literature on the practice of educational administration", Review of Educational Research, 70(1), pp55-81, 2000.

[6] J. Waterfield, and B. West, B., Inclusive Assessment in Higher Education: A Resource for Change, University of Plymouth, Plymouth, 2006.

[7] H. May, and K. Bridger, Developing and Embedding Inclusive Policy and Practice in Higher Education, Higher Education Academy, York, 2010.

[8] M. Osborne, "Policy and practice in widening participation: A six country comparative study of access as flexibility”, International Journal of Lifelong Education, 22(1), pp43-58, 2003.

[9] V.L. O'Donnell, J. Tobbell, R. Lawthom, and M. O'Neill, "Transition to postgraduate study: Practice, participation and the widening participation agenda", Active Learning in Higher Education, 10(1), pp29-43, 2009.

[10] L. Florian, and K. Black-Hawkins, "Exploring inclusive pedagogy", British Educational Research Journal, 37(5), pp813-828, 2011.

[11] U. Bronfenbrenner, The Ecology of Human Development: Experiments by Nature and Design, Harvard University Press, Cambridge: MA, 1979. 
[12] U. Bronfenbrenner, "The bioecological theory of human development”, in U. Bronfenbrenner (Ed.), Making Human Beings Human: Bioecological Perspectives on Human Development (pp. 3-15), Sage, Thousand Oaks: CA, 2005.

[13] E. Wenger, Communities of Practice, Cambridge University Press, Cambridge: England, 1998.

[14] V.L. O’Donnell, and J. Tobbell, “The transition of adult students to Higher Education: Legitimate peripheral participation in a community of practice?”, Adult Education Quarterly, 57(4), pp312-328, 2007.

[15] J. Tobbell, and V.L. O’Donnell, “Theorising educational transitions: Communities, practice and participation”, Paper presented at the Socio-Cultural Theory in Educational Research and Practice Conference, Manchester: UK, September 2005.

[16] J. Tobbell, V.L. O'Donnell, and M. Zammit, "Exploring transition to postgraduate study: shifting identities in interaction with communities, practice and participation”, British Educational Research Journal, 36(2), pp261-278, 2010.

[17] A. Sayer, “Abstraction: A realist interpretation”, In M. Archer, R. Bhaskar, A. Collier, T. Lawson, and A. Norrie (Eds.), Critical Realism: Essential Readings, pp120-143, Routledge, London, 1998.

[18] S.B. Merriam, and E. Simpson, A guide for Research for Educators and Trainers of Adults, Kreiger, Florida, 1995.

[19] A. Strauss, and J. Corbin, Basics of Qualitative Research: Techniques and Procedures for Developing Grounded Theory, Sage, Thousand Oaks: Ca, 1998.

[20] G. Anderson, Fundamentals of Educational Research, Routledge Falmer, London, 2002. 